\title{
Level of Stress and Caregiver Burden among Caregivers of Cerebral Palsy Children in Lahore City
}

\author{
Saba Rani ${ }^{1}$, Sarah Ehsan ${ }^{2}$, Hafiz Sheraz Arshad ${ }^{3}$ \\ ${ }^{1}$ Physical Therapist, Azra Naheed Medical College, Department of Physical Therapy, Main Raiwind Road, Lahore \\ ${ }^{2}$ Senior lecturer, Azra Naheed Medical College, Department of Physical Therapy, Main Raiwind Road, Lahore \\ ${ }^{3}$ Head of Department/Assistant Professor Azra Naheed Medical College, Department of Physical Therapy, Main Raiwind Road, Lahore
}

\begin{abstract}
The objective of this study was to assess the level of stress and caregiver burden among caregivers of Cerebral palsy children in Lahore city. This was an observational cross sectional study, conducted at physical therapy OPD ofChildren's Hospital Lahore and Fatima Memorial Hospital Lahore. Study was completed within 3 months after the approval from ethical review committee. Data was collected from caregivers of 196 cerebral palsy children. Self-administered questionnaires based on scales named as caregiver burden inventory and caregiver stress self-assessment were used to find out the level of stress and caregiver burden. The majority of cerebral palsy children were females (52.55\%). Total mean score for care-giver stress self-assessment scale was 37.04 (SD =6.26). And the total mean score for care-giver burden inventory was $47.84(S D=12.08)$. The response on individual items that was rated highest on caregiver stress self-assessment scale was "Afraid of what future hold for loved one" $2.71(S D=.978)$. The response on individual item that was rated highest on sub scale (time dependency) of care-giver burden inventory was "He/she needs my help to perform many daily tasks" $2.82(S D=.872)$. The caregivers of cerebral palsy children experienced moderate level of stress owing to the care-giving process. Most of caregivers were not satisfied with their emotional health, social relationships, physical health, their child's development and dependency of their child.
\end{abstract}

Keywords: Caregiver burden, Cerebral Palsy, Quality of life, Self-assessment, Stress

\section{Introduction}

\subsection{Overview}

Caregiver strain is the stress which a caregiver has to deal while taking care of a family member who is having any disorder. [1]

Cerebral Palsy is the most common developmental disorder in children. Cerebral palsy is seen in 2.5 per 1000 births in a year. [2]

For taking care of any child, time and money are important resources that are required and in case of disabled child the requirement of these resources are increased. Most of the caregivers manage well with the increased demand of resources but those who failed to cope well usually lead toward depression, burden and stress. [3]

Caregivers that belong to the children having different disorder usually have the possibility of occurrence of psychological stress. Parents whose children have developmental delay have lower rate of well-being and high rate of emotional stress. While taking care of the child, caregivers have to deal with challenges that occur with the condition of any disorder like developmental disorders. [4]

Vast knowledge about the disorder is required to caregiver in order to take better care and provide good service to their child. Caregivers are supposed to use new strategies to fulfill their role. To present caregiver's role the important factors are physical and psychological stability of caregiver and strong financial status. [5]

Recently a study was conducted to explore the children's characteristics that include the diagnosis of problem, behavior difficulty and functioning that lead to mental stress and burden in caregiver's life and to check the strain of caregiver while raising a child with some disorder. [5]

In past, with help of standard tools different studies were conducted in different countries to explore the reasons behind poor health and mental stress of caregiver. In a previous study it is 2 stated that while taking long term care of patient the caregiver naturally develop poor physical health and emotional stress. The caregivers who developed high level of stress seem to have taken care of their child in most hours of the day and night. Although in another research it has been clearly stated that as the child's demands increase with age it will automatically affect the health, well-being and mental health of the parent or caregiver. [5]

Previously a study showed that care givers of cerebral palsy child had been stressed, angry, tired and embarrassed due to their child's behavior. Sometimes except the child's behavior there are some other reasons for de-motivation of care giver like environmental issues, culture system, socioeconomic status and social support. Research has indicated that level of stress and burden correlate with level of severity of disease. [6]

A previous research has reported that any complicated, demanding and unsuitable condition of child can generate 


\section{International Journal of Science and Research (IJSR) \\ ISSN (Online): 2319-7064}

Index Copernicus Value (2013): 6.14 | Impact Factor (2015): 6.391

feeling of stress and burden in caregiver. This stress and burden can affect the care givers physical and emotional health along with social life. One other leading factor of stress is depression of partner. To overcome this situation the care givers (both parents) should encourage and appreciate each other's role in care giving. [7]

All exiting researches support that disabled child care can lead to stress and burden of caregiver. Poor physical and emotional health is associated with child's behavior, short temperament of child and severity of child's disability. [3]

In a recent study, a new concept stated that the caregiver burden can be reduced with the support of the doctor that is treating the child as well as dividing the care-giving hours between parents of child. This concept can be useful in a natural way for developing the strength and positive strategies for parents to deal with their child. [8]

However, according to Thompson and Gustafson if there is enough family income and balanced time management for care-giving, the factors of depression, stress and burden could be reduced. [9]

In most of the previous studies it has been seen that caregivers develop stress and burden while taking care of their children with cerebral palsy. As research on level of stress and caregiver burden among caregivers of Cerebral palsy children have not been conducted in Pakistan yet so this research will be performed within the areas of Lahore.

\subsection{Objective}

The objective of this study was to assess the level of stress and caregiver burden among caregivers of Cerebral palsy children in Lahore city.

\subsection{Rationale}

This study would be helpful to generate awareness and better understanding the level of stress and caregiver burden among the caregivers of cerebral palsy children so they could take better care of children with cerebral palsy.

\subsection{Operational definitions}

\subsubsection{Caregiver Burden inventory}

Caregiver burden is burden which a caregiver/parent has to manage while taking care and fulfilling the needs of cerebral palsy children. This burden has poor effect on caregiver's physical and mental health. The level of caregiver burden among caregivers of cerebral palsy children was evaluated by using the scale named as The Caregiver Burden Inventory. This was easy and quick tool with 24 questions. And every question had score between 0 and 4 . This scale measured the burden of caregiver and it covered psychological and economic domains of the burden of caregiver. This scale had good reliability that was 0.71 and validity was 0.94 . [10]

\subsubsection{Caregiver stress self-assessment scale}

The level of stress that caregiver deal while managing the cerebral palsy children was calculated by scale named as caregiver stress self -assessment scale. This scale was easy to use. This scale had 20 items and it had scores between 0 and 4 . The reliability of this scale was 0.78 . [11]

\subsection{Materials and methods}

\subsubsection{Study design}

This study was an observational, cross-sectional study

\subsubsection{Setting}

Data was collected from physical therapy departments of The Children's hospital Lahore and Fatima Memorial Hospital (FMH)

\subsubsection{Study population}

Caregivers of cerebral palsy children

\subsubsection{Duration of study}

This study was completed in 3 months after the approval from ethical review board.

\subsubsection{Sample Size}

Prevalence of cerebral palsy was 2.5 per 1000 birth and total population of Pakistan in 0-14 years is 65393715 (index mundi, 2014)

And after calculation from "Raosoft" sample size was $\mathbf{1 9 6}$.

- Margin of error was 5\%

- Confidence interval was 95\%

- Estimated population size was 163484

- Response distribution was $85 \%$

Formula used for calculation was:

$X=Z\left({ }^{c} / 100\right)^{2} r(100-r)$

$N=N x /((N-1) E 2+x)$

$E=\operatorname{Sqrt}[(N-n) x / n(N-1)]$

1.5.6. Sampling Technique

Probability, Simple random sampling was used.

\subsubsection{Eligibility}

\subsubsection{Inclusion criteria}

- Father or mother or any other relation who spends at least 6 to 10 hours with the cerebral palsy child.

- Children with CP of any type.

- Caregivers of Cerebral palsy children between the ages of 3 to 8 years.

\subsubsection{Exclusion criteria}

Caregivers with diagnosed chronic illness.

\subsubsection{Data collection}

After permission from ethical review board committee of the concerned organization data was collected from caregivers of 196 cerebral palsy children who were fulfilling the inclusion criteria from Children's Hospital Lahore and Fatima Memorial Hospital Lahore. First of all Informed consent was taken from the caregivers of cerebral palsy children. And then they were given a self-administrated questionnaire.. The questionnaire was explained by researcher to caregivers who had any difficulty to understand the questions. The questionnaire was based on scales named as caregiver burden inventory and caregiver

\section{Volume 5 Issue 4, April 2016}




\section{International Journal of Science and Research (IJSR) \\ ISSN (Online): 2319-7064 \\ Index Copernicus Value (2013): 6.14 | Impact Factor (2015): 6.391}

stress self-assessment scale. Caregiver burden inventory had five subscales that are time dependency, emotional health, development, social relationship and physical health. All subscales had 4-5 questions and every question of this scale had $0-4$ options that caregiver had to mark according to his/her opinion. The second scale used was caregiver stress self-assessment scale, it had 20 questions. All questions had 5 options that are never, rarely, sometimes, quite frequently and nearly always. The caregiver had to select one best option. The questionnaire took almost 15 minutes to fill in the required information.

\subsubsection{Ethical Consideration}

Ethical approval was taken by the hospital form where data was supposed to be collected and informed consent was taken form caregivers. The behavior of researcher was professional and within ethical values.

\subsubsection{Statistical procedure}

The collected data was analyzed through SPSS version 20. Frequency tables and descriptive statistics were used for analysis of data.

\section{Results}

Out of 196 majority of the cerebral palsy children (52.55\%) were females.

Table 1: Descriptive statistics of age of children and hours of caregiving

\begin{tabular}{|c|c|c|c|}
\hline & Mean \pm SD & Minimum & Maximum \\
\hline Age of children & $5.046 \pm 1.54$ & 3 & 8 \\
\hline Number of hours in caregiving & $7.97 \pm 1.54$ & 6 & 10 \\
\hline
\end{tabular}

* $\mathrm{SD}=$ Standard deviation

The mean age of cerebral palsy children in years was 5.046 $(\mathrm{SD}=1.54)$ while minimum age was 3 and maximum age was 8 years.

The mean for the number of hours in care giving was 7.97 $(\mathrm{SD}=1.54)$. Minimum hours for caregiving were 6 and maximum hours were 10 .

Table 2: Total mean score for Care-giver stress selfassessment scale

\begin{tabular}{|c|c|c|c|}
\hline & Mean \pm SD & Minimum & Maximum \\
\hline $\begin{array}{c}\text { Care giver stress self- } \\
\text { assessment score }\end{array}$ & $37.04 \pm 6.26$ & 21 & 58 \\
\hline
\end{tabular}

* $\mathrm{SD}=$ Standard deviation

Total mean score for care-giver stress self-assessment scale was 37.04 (SD =6.26). Minimum score was 21 and maximum was 58 .

On individual items, the three items that were rated highest on caregiver stress self- assessment scale were "Afraid of what future hold for loved one" $2.71(\mathrm{SD}=.978)$, "Loved one is dependent on you" $2.6(\mathrm{SD}=.915)$ and "Do you feel that your loved one asks for more help than he/she needs" 2.26 $(\mathrm{SD}=.938)$.

The three responses on individual items that were rated the lowest on caregiver stress self- assessment scale were "You want to leave the care of loved one to someone else" 1.62 $(\mathrm{SD}=.584)$, "Uncomfortable about having friends over because of loved one" $1.59(\mathrm{SD}=.655)$ and "Don't have much privacy because of loved one" $1.55(\mathrm{SD}=.667)$.

Table 3: Total mean score of subscale (time dependency) for care-giver burden inventory

\begin{tabular}{|c|c|c|c|}
\hline & Mean \pm SD & Minimum & Maximum \\
\hline Time dependency score & $12.43 \pm 4.44$ & 5 & 47 \\
\hline
\end{tabular}

* $\mathrm{SD}=$ Standard deviation

Total mean score of subscale (time dependency) for caregiver burden inventory was 12.43 ( $\mathrm{SD}=4.44)$. Minimum score was 5 and maximum was 47.

The response on individual item that was rated highest on sub scale (time dependency) of care-giver burden inventory was "He/she needs my help to perform many daily tasks" $2.82(\mathrm{SD}=.872)$

The response on individual item that was rated lowest on subscale (time dependency) of care giver burden inventory was "I don't have a minute's break from his/her chores" 2.09 $(\mathrm{SD}=2.36)$.

Table 4: Total mean score of subscale (emotional health) for care-giver burden inventory

\begin{tabular}{|l|l|l|l|}
\hline & Mean \pm SD & Minimum & Maximum \\
\hline Emotional heath score & $\mathbf{8 . 9 5} \pm \mathbf{2 . 6 9 9}$ & $\mathbf{2}$ & $\mathbf{1 9}$ \\
\hline
\end{tabular}

* $\mathrm{SD}=$ Standard deviation

Total mean score of subscale (emotional health) for caregiver burden inventory was 8.95 ( $\mathrm{SD}=2.699)$. Minimum score was 2 and maximum was 19.

The response on individual item that was rated highest on sub scale (emotional health) of care-giver burden inventory was "I feel angry about my interactions with him/her" 1.98 $(\mathrm{SD}=.832)$. The response on individual item that was rated lowest on subscale (emotional health) of care giver burden inventory was "I resent him/her" $1.54(\mathrm{SD}=.761)$.

Table 5: Total mean score of subscale (development) for care-giver burden inventory

\begin{tabular}{|l|l|l|l|}
\hline & Mean \pm SD & Minimum & Maximum \\
\hline Development score & $\mathbf{9 . 6 5} \pm \mathbf{3 . 0 9}$ & $\mathbf{3}$ & $\mathbf{1 8}$ \\
\hline
\end{tabular}

* $\mathrm{SD}=$ Standard deviation

Total mean score of subscale (development) for care-giver burden inventory was 9.65 ( $\mathrm{SD}=3.09)$. Minimum score was 3 and maximum was 18 .

The response on individual item that was rated highest on sub scale (development) of care-giver burden inventory was "I feel I am missing out on life"2.16 (SD=.796).

The response on individual item that was rated lowest on sub scale (development) of care-giver burden inventory was "I expected things would be different at this point of life" 1.81 $(\mathrm{SD}=.813)$. 


\section{International Journal of Science and Research (IJSR) \\ ISSN (Online): 2319-7064 \\ Index Copernicus Value (2013): 6.14 | Impact Factor (2015): 6.391}

Table 6: Total mean score of subscale (social relationship) for care-giver burden inventory

\begin{tabular}{|l|c|c|c|}
\hline & Mean \pm SD & Minimum & Maximum \\
\hline Social relationship score & $\mathbf{8 . 9 7} \pm \mathbf{2 . 6 9}$ & $\mathbf{4}$ & $\mathbf{1 8}$ \\
\hline
\end{tabular}

$* \mathrm{SD}=$ Standard deviation

Total mean score of subscale (social relationship) for caregiver burden inventory was 8.97 ( $\mathrm{SD}=2.69$ ). Minimum score was 4 and maximum was 18 .

The response on individual item that was rated highest on sub scale (social relationships) of care-giver burden inventory was "I don't get along with other family members as before" $2.07(\mathrm{SD}=.808)$.

The response on individual item that was rated lowest on sub scale (social relationships) of care-giver burden inventory was "I feel resentful of other relatives who don't help" 1.59 $(\mathrm{SD}=.728)$.

Table 8: Total mean score of subscale (physical health) for care-giver burden inventory

\begin{tabular}{|l|c|c|c|}
\hline & Mean \pm SD & Minimum & Maximum \\
\hline Physical heath score & $\mathbf{7 . 8 5} \pm \mathbf{2 . 6 8}$ & $\mathbf{4}$ & $\mathbf{1 5}$ \\
*SD $=$ Standard deviation
\end{tabular}

Total mean score of subscale (physical health) for care-giver burden inventory was 7.85 ( $\mathrm{SD}=2.68)$. Minimum score was 4 and maximum was 15 .

The response on individual item that was rated highest on sub scale (physical health) of care-giver burden inventory was "I am not getting enough sleep" $2.42(\mathrm{SD}=.828)$

The response on individual item that was rated lowest on sub scale (physical health) of care-giver burden inventory was "I'm physically tired" $1.76(\mathrm{SD}=.918)$.

Table 8: Total mean score for care-giver burden inventory

\begin{tabular}{|c|c|c|c|}
\hline & Mean \pm SD & Minimum & Maximum \\
\hline $\begin{array}{c}\text { Care giver burden } \\
\text { inventory score }\end{array}$ & $47.84 \pm 12.08$ & 29 & 89 \\
\hline
\end{tabular}

* $\mathrm{SD}=$ Standard deviation

Total mean score for care-giver burden inventory was 47.84 $(\mathrm{SD}=12.08)$. Minimum score was 29 and maximum was 89 .

\section{Discussion}

The role of caregiver in management of cerebral palsy children is necessary that's why the health of caregiver while taking care of such children is also necessary. This research was done for evaluating the level of stress and burden in caregivers of cerebral children in Lahore city.

The highly rated response of caregiver "I feel that I am missing out on life" and "I don't get along with other family members as before" is supported in a previous study that caregivers of cerebral palsy children felt like they had been limited to the care of child only and their social relationships have been spoiled completely as their child's care doesn't give them escape from the situation. [12]
The response of questions like "Don't have enough money to take care for your loved one" and "I feel angry about my interactions with him/her" is supported in a study that is low socio economic status of caregiver plays major role in stress and burden of care giver. If caregiver is already depressed and tensed because of financial issues then definitely the level of stress and burden will increase naturally. And anger while taking care will be due of this depression. [12]

Highly rated responses "Do you feel that your loved one asks for more help than he/she needs" and "Loved one is dependent on you" are revealed in previous study that the demands and needs of cerebral palsy child increase as the age of child increases. He/she always wanted to be surrounded by the caregiver for sake of his/her satisfaction and wanted to stay dependent to get more attention so this has a negative impact on life of caregiver. [13]

A previous study stated that the leading factor of stress and burden among caregivers is their poor physical and emotional health that while taking care of child they don't get enough time for themselves. It is especially seen in mothers of child because she spent more time/hours with the child [14]. The current study has exposed somewhat similar outcome about the highest rated response "I'm not getting enough sleep" and a lowest rated response "I'm physically tired".

A past study showed that the level of stress in caregivers of cerebral palsy children is severe and the mental status of caregiver was also affected badly [15]. However, these results are inconsistent with the present study due to difference in population and use of the different scale.

The results of this study are based on care givers responses from few hospitals of Lahore. So this is the limitation of present study that due to the large number of population of Pakistan the sample size was restricted within the areas of Lahore.

Furthermore, as results are based on self-administrated questionnaire so most of time the caregiver may have given answer to please the researcher. And there was less discussion with the caregiver due to close ended questions in the scale.

In addition, few caregivers had extra stress and burden because of their low socio economic status. It is a limitation in a way that if caregiver is already dealing with different issues in life so care of cerebral palsy child will be not be the only reason for stress.

\section{Conclusion}

This study concludes that the caregivers of cerebral palsy children experienced moderate level of stress owing to the care-giving process. Most of caregivers were not satisfied with their emotional health, social relationships, physical health, their child's development and dependency of their child. 


\section{International Journal of Science and Research (IJSR)}

ISSN (Online): 2319-7064

Index Copernicus Value (2013): 6.14 | Impact Factor (2015): 6.391

\section{References}

[1] Dambi JM, Jelsma J, Mlambo T. Caring for a child with Cerebral Palsy: The experience of Zimbabwean mothers. African Journal of Disability. 2015;4(1):10 pages.

[2] Ketelaar M, Volman MJ, Gorter JW, Vermeer A. Stress in parents of children with cerebral palsy: what sources of stress are we talking about? Child Care Health Dev. 2008;34(6):825-9. Epub 2008/10/31.

[3] Brehaut JC, Kohen DE, Raina P, Walter SD, Russell DJ, Swinton M, et al. The health of primary caregivers of children with cerebral palsy: how does it compare with that of other Canadian caregivers? Pediatrics. 2004;114(2):e182-e91.

[4] Estes A, Munson J, Dawson G, Koehler E, Zhou XH, Abbott R. Parenting stress and psychological functioning among mothers of preschool children with autism and developmental delay. Autism. 2009;13(4):375-87. Epub 2009/06/19.

[5] Murphy NA, Christian B, Caplin DA, Young PC. The health of caregivers for children with disabilities: caregiver perspectives. Child Care Health Dev. 2007;33(2):180-7. Epub 2007/02/13.

[6] Mugno D, Ruta L, D'Arrigo VG, Mazzone L. Impairment of quality of life in parents of children and adolescents with pervasive developmental disorder. Health and quality of life outcomes. 2007;5(1):1.

[7] Raina P, O'Donnell M, Schwellnus H, Rosenbaum P, King $\mathrm{G}$, Brehaut $\mathrm{J}$, et al. Caregiving process and caregiver burden: conceptual models to guide research and practice. BMC pediatrics. 2004;4(1):1.

[8] Wang H-Y, Jong Y-J. Parental stress and related factors in parents of children with cerebral palsy. The Kaohsiung Journal of Medical Sciences. 2004;20(7):334-40.

[9] Manuel J, Naughton MJ, Balkrishnan R, Smith BP, Koman LA. Stress and adaptation in mothers of children with cerebral palsy. Journal of Pediatric Psychology. 2003;28(3):197-201.

[10] Novak M, Guest C. Application of a multidimensional caregiver burden inventory. Gerontologist. 1989;29(6):798-803. Epub 1989/12/01.

[11]Epstein-Lubow G, Gaudiano BA, Hinckley M, Salloway S, Miller IW. Evidence for the validity of the American Medical Association's caregiver selfassessment questionnaire as a screening measure for depression. J Am Geriatr Soc. 2010;58(2):387-8. Epub 2010/04/08

[12] Mugno D, Ruta L, D'Arrigo VG, Mazzone L. Impairment of quality of life in parents of children and adolescents with pervasive developmental disorder. Health and quality of life outcomes. 2007;5(1):1.

[13] Murphy NA, Christian B, Caplin DA, Young PC. The health of caregivers for children with disabilities: caregiver perspectives. Child: care, health and development. 2007;33(2):180-7.

[14] Raina P, O'Donnell M, Schwellnus H, Rosenbaum P, King $G$, Brehaut $J$, et al. Caregiving process and caregiver burden: conceptual models to guide research and practice. BMC pediatrics. 2004;4(1):1.

[15] Mobarak R, Khan NZ, Munir S, Zaman SS, McConachie H. Predictors of stress in mothers of children with cerebral palsy in Bangladesh. Journal of Pediatric Psychology. 2000;25(6):427-33.

\section{Author Profile}

Saba Rani is Physical Therapist, Azra Naheed Medical College, Department of Physical Therapy, Main Raiwind Road,, Lahore

Sarah Ehsan is Senior Lecturer, Azra Naheed Medical College, Department of Physical Therapy, Main Raiwind Road,, Lahore

Hafiz SherazArshad is Head of Department/Assistant Professor, Azra Naheed Medical College, Department of Physical Therapy, Main Raiwind Road, Lahore 